\title{
Saving and habit formation: evidence from Dutch panel data
}

\author{
Rob Alessie - Federica Teppa
}

Received: 19 March 2007 / Accepted: 18 June 2008 / Published online: 24 March 2009

(C) The Author(s) 2009. This article is published with open access at Springerlink.com

\begin{abstract}
This paper focuses on the role of habit formation in individual preferences. In this study, the model of Alessie and Lusardi (Econ Lett 55:103-108, 1997) and its extension by Guariglia and Rossi (Oxf Econ Pap 54:1-19, 2002) are considered. Our empirical specifications are based on their closed-form solutions, where current saving is expressed as a function of lagged saving and other regressors. In our study, we use a longitudinal data set from the Netherlands that allows us to disentangle the role of habit formation from unobserved heterogeneity. Contrary to most other studies using survey data, we find evidence in favor of habit formation. However, the magnitude of the habit formation coefficient is rather small. Income uncertainty seems to affect saving behavior of Dutch households.
\end{abstract}

Keywords Habit formation · Permanent income · Precautionary savings · Panel data

JEL Classification D91

\footnotetext{
R. Alessie $(\varangle)$

University of Groningen \& Netspar \& Tinbergen Institute, Faculty of Economics and Business, P. O. Box 800, 9700 AV Groningen, The Netherlands

e-mail: r.j.m.alessie@rug.nl

F. Teppa

De Nederlandsche Bank \& Netspar, Economics and Research Division,

Postbus 98, 1000 AB Amsterdam, The Netherlands

e-mail: f.teppa@dnb.nl
} 


\section{Introduction}

The concept of habit formation relies on the idea that one's own past consumption might have an effect on the utility yielded by current consumption: for a given level of current consumption, a larger habit stock lowers utility. Habits were first introduced in the context of demand systems (see, e.g. Pollak 1970). In the literature a distinction between two types of habits has been made: myopic (or naive) and rational. In the first case (see, e.g. Pollak 1970), consumers are not aware of the effects that their current consumption decisions will have on their future marginal rates of substitution between goods and as a consequence their behavior may be time-inconsistent. In the second case (Spinnewijn 1981), consumers are aware of the habit forming effect of current consumption.

The presence of habit formation may provide an appealing (partial) explanation to a number of anomalous empirical findings contrasting some of the permanent income model's predictions, such as the "excess sensitivity" of aggregate consumption growth relative to current labor income growth, ${ }^{1}$ its "excess smoothness" relative to lagged labor income growth, ${ }^{2}$ the equity premium ${ }^{3}$ puzzle, and the risk-free rate ${ }^{4}$ puzzle (Abel 1990; Campbell and Cochrane 1999). Moreover, Carroll et al. (2000) show that if one allows for habit formation, then standard growth models can be reconciled with the empirical evidence suggesting that high growth leads to high saving, rather than the other way around.

In general, mixed conclusions about the strength of habit formation arise from past studies of time-nonseparable preferences based on aggregate consumption data. A number of studies using aggregate consumption data (see e.g. Dunn and Singleton 1986) display very little evidence of habits. However, other studies concerning US data (Ferson and Constantinides 1991) lead to a different conclusion.

One of the most common approaches in micro-econometric studies used to test the presence of habit formation has been the Euler equation approach. It focuses on a specific first-order condition implied by the optimization problem faced by a generic consumer, allowing the estimation of preference parameters. In this strand of literature, Hotz et al. (1988) examine whether intertemporally nonseparable utility functions are

\footnotetext{
1 The permanent income model predicts that consumption changes should be orthogonal to predictable, or lagged, income changes. Yet, the correlation between consumption growth and lagged income growth seems to be one of the most robust features of aggregate data (Flavin 1981; Campbell and Deaton 1989; Runkle 1991).

2 The permanent income model predicts that consumption growth should be more volatile than income growth if aggregate income growth has positive serial correlation. Yet, aggregate consumption growth seems to be much smoother than aggregate income growth (Campbell and Deaton 1989). Notice however that a number of studies based on household-level data (e.g. Runkle 1991) show a strong correlation between consumption growth and lagged income growth.

${ }^{3}$ Under time-separable utility, Mehra and Prescott (1985) could not find a plausible pair of subjective discount rate and relative risk aversion of the representative consumer to match the mean of the annual real rate of interest and of the equity premium in a US sample over a 90-year period. That is, stocks were not sufficiently riskier than Treasury bills to explain the spread of their returns.

${ }^{4}$ Weil (1989) found that in the same sample used by Mehra and Prescott (1985), although individuals like consumption to be very smooth and although the risk-free rate is very low, they still save enough so that per-capita consumption grows rapidly.
} 
important in characterizing microdata on life-cycle labor supply behavior among white male workers in the U.S. They find empirical support for the hypothesis that agents' preferences directly depend upon past leisure decisions and for the relatively simple specification of nonseparable preferences. More recently, Meghir and Weber (1996) argue that the within marginal rate of substitution function can be used as a control when evaluating results obtained using the intertemporal Euler equation. They use a large sample of US households, drawn from twelve years of the Consumer Expenditure Survey to model the intertemporal and within period allocation of expenditure on food in the home, transport, and services, and they allow for the presence of liquidity constraints. Their findings show no empirical support for intertemporal non-separability of preferences over the three categories of consumption. Similarly, Dynan (2000) finds no evidence of habit formation at the annual frequency. Her analysis on food consumption data from the Panel Study on Income Dynamics indicates that habit formation has at most a limited impact on consumers' behavior. This finding is robust to a number of changes in the model's specification. However, both these studies do not control explicitly for time invariant unobserved heterogeneity across households, that may lead to a spurious relationship between future and past consumption. Using Spanish panel data, Carrasco et al. (2005) build on the study by Meghir and Weber (1996) and show how crucial it is to account for fixed effects when testing for the presence of habit formation in consumption decisions. ${ }^{5}$ If fixed effects are not taken into account, they find evidence of intertemporally separable preferences. ${ }^{6}$ However this result is not robust once they control for time invariant unobserved heterogeneity across households: in this case, a significant role of habit formation is found. More recently, Malley and Molana (2006) use U.S. time series data on consumers' expenditures and disposable income from the U.S. National Income and Product Accounts covering the period 1929-2001 to estimate the path of aggregate consumption implied by the permanent income model. They find a significant and robust role of habit formation.

An alternative approach to the Euler equation is adopted by Alessie and Lusardi (1997), who derive closed-form solutions for consumption (and saving) under the assumption of CARA within period preferences. Closed-form solutions for consumption and saving allow a better understanding of some of the issues concerning those variables, as they provide a rich specification that extends some of the previous results in the literature. A problem with the model of Alessie and Lusardi (1997) is that it does not preclude negative consumption. A detailed description of Alessie and Lusardi's model is provided in Sect. 2.

Guariglia and Rossi (2002) generalize Weil's non-expected utility model (1993) by allowing for habit formation. They obtain a closed-form solution for saving as a function of, among other things, lagged consumption. Their model can be seen as an extension of Alessie and Lusardi (1997), as in the closed form solution of Alessie and Lusardi (1997) the lagged consumption variable does not appear as an explanatory variable. Guariglia and Rossi (2002) then derive an Euler equation of consumption changes, where current consumption changes depend on lagged changes and labor

\footnotetext{
5 Carrasco et al. (2005) focus on the same consumption items as Meghir and Weber (1996), namely food at home, transport and services.

6 This result is in line with both Meghir and Weber (1996) and Dynan (2000).
} 
income risk. ${ }^{7}$ They estimate this Euler equation using food consumption data from the British Household Panel Survey for the period 1992-1997, by allowing for unobserved time invariant heterogeneity in preferences. They find that both labor income risk and past changes in consumption are important in determining current changes in consumption. In particular, their estimation results suggest that the lagged changes in consumption display a strong statistically significant negative effect on the current changes. This suggests that the utility function exhibits durability in Deaton (1992) sense, rather than habit formation. It is worthwhile saying that Guariglia and Rossi's empirical model can also be justified by the model by Alessie and Lusardi (1997). In other words Guariglia and Rossi (2002) cannot infer empirically whether or not their extension of Weil's model describes household behavior in a better way than the model of Alessie and Lusardi (1997).

In this paper, we estimate the models of Alessie and Lusardi (1997) and Guariglia and Rossi (2002). Our empirical models are based on their closed-form solutions, ${ }^{8}$ where saving is expressed as a function of lagged saving and other regressors. We opt for this choice because the closed form solution embodies more information about the habit formation model than the Euler equation does, and allows for a more powerful test of the validity of the habit formation model than the alternative approach. For example, contrary to Guariglia and Rossi (2002) we are able to discriminate empirically between the models of Alessie and Lusardi (1997) and Guariglia and Rossi (2002). However, we have to qualify a bit the remark about the advantages of using the closed form solution in the empirical exercise: the closed form solution approach relies more heavily on proxy variables (e.g. we need a proxy for the expected discounted value of future income changes).

The remainder of the paper is organized as follows. In Sect. 2, we present the theoretical model. Section 3 describes our dataset, Sect. 4 provides the empirical implementation, and Sect. 5 contains the empirical results. Section 6 concludes the paper.

\section{The theoretical model for habit formation and precautionary saving}

In this section we describe the theoretical model we will use for empirical tests. We strictly refer to Alessie and Lusardi (1997) model of habit formation, in its precautionary saving specification.

The reference model is the one by Caballero (1990), with a Constant Absolute Risk Aversion (CARA) utility function and an uncertain non-capital income (income is assumed to be a strictly exogenous variable), following a moving-average process with $\psi_{i}$ representing the $i$ th MA coefficient. Hence:

$$
E_{t} y_{\tau}-E_{t-1} y_{\tau}=\psi_{\tau-t} w_{t}, \quad \tau \geq t
$$

\footnotetext{
${ }^{7}$ In the derivation of the Euler equation, Guariglia and Rossi (2002) assume that the rate of time preference equals the real interest rate.

8 Alternatively, we could have used the Euler-equation approach (see e.g., Guariglia and Rossi (2002) and Dynan (2000)).
} 
where $\psi_{0}=1, \sum_{\tau=t}^{\infty}(1+r)^{t-\tau} \psi_{\tau-t}<\infty$ and $w_{t}$ is an i.i.d. innovation. Alessie and Lusardi (1997) extend Caballero (1990) model by allowing for habit formation.

Assuming an infinite planning horizon, households choose current and future consumption in such a way that the following expected intertemporal non-additive utility function is maximized:

$$
\operatorname{Max} E_{t} \sum_{\tau=t}^{\infty}(1+\rho)^{t-\tau}\left(-\frac{1}{\theta} e^{-\theta\left(c_{\tau}-\gamma c_{\tau-1}\right)}\right)
$$

subject to an intertemporal budget constraint ${ }^{9}$ :

$$
\sum_{\tau=t}^{\infty}(1+r)^{t-\tau} c_{\tau}=(1+r) A_{t-1}+\sum_{\tau=t}^{\infty}(1+r)^{t-\tau} y_{\tau}
$$

where $A_{t-1}$ and $c_{t-1}$ are given. $E_{t}$ is the expectations operator, $c_{\tau}$ denotes consumption in period $\tau, y_{\tau}$ is non-capital income, $A_{\tau}$ is non-human wealth at the end of period $\tau, r$ is the real fixed interest rate and $\rho$ is the rate of time preference (in the derivation below, we assume that $r=\rho$ ). Current utility depends not only on current consumption, but also on consumption a period ago. Note that the infinite horizon over which the optimization occurs is a crucial assumption, which might not be realistic. Angelini (2009), however, provides an exact closed form solution for optimal consumption in a finite horizon life-cycle model with CARA preferences. As we will discuss below, the predictions of Angelini's model are rather similar to those of Alessie and Lusardi (1997).

Define $c_{\tau}^{*}=c_{\tau}-\gamma c_{\tau-1}$. We can solve the model by expressing everything in terms of $c_{\tau}^{*}$. We can re-write the intertemporal utility function (2) as follows:

$$
\operatorname{Max} E_{t} \sum_{\tau=t}^{\infty}(1+\rho)^{t-\tau}\left(-\frac{1}{\theta} e^{-\theta c_{\tau}^{*}}\right)
$$

Note that the utility function is additively separable in $c_{\tau}^{*}$. The assumption of an infinite planning horizon allows us to rewrite the intertemporal budget constraint (3) in the following way:

$$
\begin{aligned}
& \sum_{\tau=t}^{\infty}(1+r)^{t-\tau} c_{\tau}^{*} \\
& \quad=-\gamma c_{t-1}+\frac{(1+r-\gamma)}{(1+r)}\left[(1+r) A_{t-1}+\sum_{\tau=t}^{\infty}(1+r)^{t-\tau} y_{\tau}\right]
\end{aligned}
$$
9 Given $A_{t-1}$, this intertemporal budget constraint is derived from a transversality condition
$\lim _{\tau \rightarrow \infty} A_{\tau}(l+r)^{t-\tau}=0$ and from the following equation:

$$
A_{\tau}=(1+r) A_{\tau-1}+y_{\tau}-c_{\tau}
$$


Given this equation, Alessie and Lusardi (1997) prove the following:

- The stochastic process of $c_{\tau}^{*}=c_{\tau}-\gamma c_{\tau-1}$ is a martingale with drift:

$$
c_{\tau}^{*}=c_{\tau-1}^{*}+\Gamma_{\tau-1}+v_{\tau}
$$

where $v_{\tau}$ denotes the innovation in consumption $c_{\tau}^{*}$ and $\Gamma_{\tau-1}$ is a measure of the effect of precautionary saving (see below).

- The relation between the consumption innovation $v_{\tau}$ and the income innovation $w_{\tau}$ can be written as:

$$
v_{\tau}=\psi^{*} w_{\tau}
$$

where $\psi^{*}=\left(1-\frac{\gamma}{1+r}\right) \frac{r}{1+r} \sum_{i=0}^{\infty} \psi_{i}(1+r)^{-i}$. This means that if habit formation is not present $(\gamma=0)$, then the consumption innovation equals the annuity value of the contemporaneous innovation in income; with habits, the consumption innovation equals $\left(1-\frac{\gamma}{1+r}\right)$ times the revision in permanent income. As a consequence, the larger the habit formation coefficient $\gamma$, the smaller $\psi^{*}$, and consequently, the less sensitive consumption is to income shocks.

- The consumption function implied by the maximization problem above has the following form:

$$
c_{t}=\frac{\gamma}{1+r} c_{t-1}+\left(1-\frac{\gamma}{1+r}\right) Y_{p t}-\frac{r}{1+r} \sum_{\tau=t+1}^{\infty}(1+r)^{t-\tau} \sum_{j=t+1}^{\tau} \Gamma_{j-1}
$$

where $Y_{p t}=\frac{r}{1+r}\left[(1+r) A_{t-1}+\sum_{\tau=t}^{\infty}(1+r)^{t-\tau} E_{t} y_{\tau}\right]$ denotes permanent income and $\Gamma_{j-1}=\frac{1}{\theta} \ln E_{j-1} \exp \left(-\theta \psi^{*} w_{j}\right)$. Equation (8) says that consumption depends on past consumption, permanent income and precautionary saving. Equation (8) is additive and precautionary saving depends on the properties of income risk. The parameter $\gamma$ affects the relative importance of the three terms. In particular, the stronger the habit, the bigger the weight put on past consumption and the lower the effect of permanent income (this is consistent with the fact that "among its potentially important empirical implications, habit formation causes consumers to adjust slowly to shocks in permanent income" (Dynan 2000)). Moreover, the impact of income uncertainty on consumption is smaller in case of strong habit formation. Notice that if $\gamma=0$ (no habit formation), the marginal propensity to consume (MPC) out of permanent income shocks (e.g. due to a permanent tax cut) is equal to one.

One might argue that the predictions presented above and our empirical results (see Sect. 5) are primarily driven by the convenient choice of the utility function (CARA preferences) and by the assumption of an infinite time horizon. However, this does not seem to be the case, as the predictions which follow from Eq. (8) are qualitatively similar to those of more general models. For instance, Carroll (2002) analyzes a habit formation model with Constant Relative Risk Aversion (CRRA) preferences. Like Alessie and Lusardi (1997), Carroll (2002) also finds 
that the MPC out of permanent income shocks is considerably lower than one if habit formation is an important phenomenon. In addition, Angelini (2009) extends the model of Alessie and Lusardi (1997) by considering a finite horizon. Her closed form solution is similar to Eq. (8), but the coefficients corresponding to permanent income and lagged consumption are age specific. However, for young and middle aged people those coefficients barely change with age. In other words, Eq. (8) seems to effectively describe the consumption behavior of such individuals.

If the model is written in terms of saving (denoted by $s_{t}$ ) rather than consumption, the closed-form solution for saving takes the following form:

$$
s_{t}=\gamma s_{t-1}+\frac{\gamma}{1+r} \Delta y_{t}-\left(1-\frac{\gamma}{1+r}\right) \sum_{\tau=t+1}^{\infty}(1+r)^{t-\tau} E_{t} \Delta y_{\tau}+\epsilon_{t}^{*}
$$

where $\epsilon_{t}^{*}=\frac{r}{1+r} \sum_{\tau=t+1}^{\infty}(1+r)^{t-\tau} \sum_{j=t+1}^{\tau} \Gamma_{j-1}$ denotes the precautionary saving term. Similarly, saving depends on past saving, current and future income changes and properties of the income process. Once again, the importance of each component is a function of $\gamma$, that is of the strength of habit. In the case of no habits $(\gamma=0)$, the equation above is the standard "saving for a rainy day" equation; when there is habit formation $(\gamma>0)$, the stronger the habit, the lower the role of future income changes and of income uncertainty and the higher the one of past saving.

Guariglia and Rossi (2002) generalize the non-expected utility model of Weil (1993) by allowing for habit formation. They obtain (see equation 10 of Guariglia and Rossi (2002)) the following closed-form solution for consumption as a function of permanent income, lagged consumption and labor income risk:

$$
c_{t}=\left(1-\frac{\gamma}{1+r}\right)\left(1-\frac{\delta-1}{r}\right) Y_{p t}+\delta \frac{\gamma}{1+r} c_{t-1}+\epsilon^{*}
$$

where $\delta=\left(\frac{1+r}{1+\rho}\right)^{\frac{1}{\alpha}}$ ( $\rho$ denotes the rate of time preference and $\frac{1}{\alpha}$ the elasticity of intertemporal substitution) and $\varepsilon^{*}\left(\varepsilon^{*}<0\right)$ denotes the precautionary saving component which depends on, among other things, the variance of future income shocks and the habit formation parameter $\gamma \cdot{ }^{10}$ Notice that if $r=\rho$, then $\delta=1$. In that case, model (10) is observationally equivalent to model (8). Model (10) implies the following saving equation:

\footnotetext{
10 See equation 11 of Guariglia and Rossi (2002). The higher the variance of future income shocks, the more negative the precautionary saving term $\varepsilon^{*}$ becomes. Like in the model of Alessie and Lusardi (1997) Guariglia and Rossi's model predicts that the larger the habit formation coefficient $\gamma$, the less sensitive consumption is to income shocks (i.e precautionary becomes less important).
} 


$$
\begin{aligned}
s_{t}= & \left(\delta-1+\gamma \frac{r+1-\delta}{1+r}\right)\left(\frac{1}{r} \Delta y_{t}+\frac{1+r}{r} s_{t-1}\right) \\
& -\left(1-\frac{\gamma}{1+r}\right) \frac{1+r-\delta}{r}\left[\sum_{\tau=t+1}^{\infty}(1+r)^{t-\tau} \Delta y_{\tau}\right]+\frac{(\gamma-1)(1-\delta)}{r} c_{t-1}-\varepsilon^{*}
\end{aligned}
$$

\section{Description of the dataset}

The empirical analysis is based on six waves of the DNB Household Survey (DHS), formerly known as the CentER Savings Survey (CSS), drawn in the Netherlands from 1993 to 1998 . The DHS is a panel survey started in 1993 and run every year. Until 1997, the DHS consisted of two samples. The first sample (REP) was intended to be representative of the Dutch population; it consists of some 2,000 households in each wave, including refreshment samples compensating for panel attrition. The second sample (HIP) was representative of the top $10 \%$ of the income distribution and initially it contained some 900 households. In 1998 on most respondents of the second sample stopped, so that since that year on the DHS includes only the REP.

The DNB Household Survey consists of five questionnaires: work and pensions, accommodation and mortgages, income and health, assets and liabilities, economic and psychological concepts. The questionnaires are sent to the respondents by modem, the respondents fill in the questionnaires at their home computers, and the answers are returned in the same way. This means that the questionnaires are self-administered and the respondents can answer the questionnaires at a time that is convenient for them.

For our purposes we focus mainly on the assets and liabilities questionnaire and the economic and psychological concepts. The former provides detailed information about forty asset and debt categories, both financial and real (a detailed description of these assets and liabilities is provided by Alessie et al. (2002)). For most of these categories, respondents are first asked to indicate whether they own the type. If they do, they then have to answer a set of questions about the amounts and the precise nature of each asset/liability. Non-response is not an issue for the ownership questions, but it is for some of the questions on the amounts. We then adopt the same methodology by Alessie et al. (2002), that is we have imputed the amounts for those who reported to be owners but did not provide an amount. The imputed values are based on amounts held in adjacent years and on regression models that relate observed amounts to household characteristics. Prediction errors are taken into account by drawing errors from the estimated error term distribution in the regression models, where full account is taken of the covariance structure of the error terms over time. For all respondents these data have been aggregated into total income per component and total asset per component. On the basis of the various income components, total gross and total net income (on the respondent level) were also computed.

The economic and psychological concepts questionnaire represents a very rich set of questions about several topics, including personal characteristics, household income, expectations about future income, attitude towards saving and saving behavior, risk perception and risk aversion, expectations for the future and comparison with 
the current situation, planning of financial matters. For our purposes, we focus on a number of questions related to saving behavior.

Equation (9) is the starting point of our empirical analysis. It should be stressed that we cannot estimate consumption equation (8) because the DHS data does not contain direct information on consumption. We now provide a description of the variables used in the estimation procedure.

1. In the DHS, the dependent variable $s_{i t}$ (saving by household $i$ in year $t$ ) can be measured as follows. First, we use information about whether any money has been put aside in the previous 12 months by an individual. Then they are asked to indicate how much money their household has put aside in the same period. In our analysis we do not use limited dependent variable estimation technique for reasons explained in footnote 11. It is therefore important to deal with "no money put aside" answers (1,907 cases out of the 6,602 cases). We have further investigated these cases by crossing them with other informative variables in the questionnaire, in order to check for potential dissaving. In particular, we have considered the following question:

"Over the past 12 months, would you say the expenditures of your household were higher than the income of the household, about equal the income of the household, or lower than the income of the household?"

Second, we treat the dependent variable, $s_{i t}$, as a continuous variable, represented by the amount of money put aside. ${ }^{11}$ We have constructed this variable as follows. For those who have claimed to have put no money aside and whose expenditures were about equal the income of the household, it was clear that they have not saved and not dissaved either. We then have imputed zero as the amount of money put aside (1,701 cases). For those who have claimed to have put no money aside and whose expenditures were higher than the income of the household, we have constructed a change in liquid financial wealth as a proxy of their dissaving and imputed that negative value as the amount of money put aside (141 observations). Finally, for those who have claimed to have put no money aside and whose expenditures were lower than the income of the household, we have constructed a change in liquid financial wealth as a proxy of their saving and imputed that (positive) value as the amount of money put aside, in order to overcome the contradiction (65 cases). In constructing the imputed variable mentioned above, we have used information about wealth. For each year, we have picked the most liquid categories for assets (checking accounts, savings arrangements, linked to a Postbank account, deposit books, savings or deposit accounts, savings certificates) net of the most liquid categories of liabilities (private loans and extended lines of credit)

\footnotetext{
11 Respondents report the amount of money put aside in classes. Out of this piece of information we have constructed a "continuous" variable by taking the mid-points for each class. Alternatively, we could have adopted a Limited Dependent Variable (LDV) technique (e.g. ordered probit) to obtain estimates of the parameters. However, our empirical habit formation model is clearly dynamic and allows for unobserved heterogeneity by including an individual effect. Obviously, some of the right hand side variables (apart from lagged saving) may be correlated with the individual effect. The estimation of LDV models which allow for both state dependence and correlated unobserved heterogeneity is notoriously difficult. Therefore, we abstain from such an approach.
} 
and then taken first differences. We have deleted extreme values in order to avoid including outliers in our imputations. ${ }^{12}$

Obviously, we could have obtained an alternative saving measure by computing the first differences in (liquid) wealth $\left(\Delta A_{t}\right)$. We will argue in the next section that using this measure may result in a spuriously negative estimate of the habit formation parameter.

2. Income change: We build a variable ("Realised income change") from the following set of questions:

A. "The total net income of your household consists of the income of all members of the household, after deduction of taxes and premiums for social insurance policies, taken as the sum total over the past 12 months. Compared to about one year ago, did the total net income of your household increase, remain about the same, or decrease?"

B. "By what percentage (approximately) has the total net income of your household increased/decreased?"

We then transform percentages into amounts and use the latter specification in the empirical estimation.

3. Expectations on income change: Two time-horizon lenghts are considered, as we exploit the following questions:

A1. "Do you think the total net income of your household will increase, remain the same, or decrease in the next 12 months?"

A2. "By what percentage do you think the total net income of your household will increase/decrease in the next 12 months?"

B1. "Do you think the total net income of your household will increase, remain the same, or decrease in the next 5 years?"

B2. "By what percentage do you think the total net income of your household will increase/decrease in the next 5 years?"

Two variables are then constructed: variable "Expected income change (next 12 months)" refers to questions A1-A2, variable "Expected income change (next 5 years)" refers to questions B1-B2. Both variables are in amounts.

4. Uncertainty on expected income change: Based on Das and Donkers (1999) and Hochguertel (2003), we exploit seven questions related to uncertainty about future income. First, respondents are asked how probable it is that next year income increases by more than $15 \%$. They can answer on a seven-point scale ranging from "very unlikely" to "very likely". The same type of question is asked for an increase of between 10 and $15 \%$, between 5 and $10 \%$, no change, a decrease of

12 One may argue that the estimation results may be "dominated" by the imputed continuous savings data for those who do not put money aside although it concerns a few observations. In order to investigate this issue, we have also created an alternative measure for saving, by imputing averages of the change in financial wealth for two classes of individuals:

- individuals who do not report putting money aside and claim that their expenditures were lower than income (average change fin. wealth $=-10,490$ );

- individuals who do not report putting money aside and claim that their expenditures were higher than income (average change fin. wealth $=9,873$ ).

This revised saving measure only takes 10 different values, namely $-10490,0,1,500,6,500,9,873,17,500$, $32,500,57,500,112,500$, and 150,000 guilders. See Sect. 5 for a summary of the estimation results using this alternative saving measure. 
between 5 and $10 \%$, a decrease of between 10 and $15 \%$ and a decrease of more than $15 \%$. We follow the suggestion of Das and Donkers (1999) and constructed probabilities for the categories of income changes in the following way:

$$
P_{j}=\frac{W_{j}}{\sum_{k=1}^{7} W_{k}}, \quad j=1, \ldots, 7
$$

where $W_{j}$ is the answer to question $j$ concerning income uncertainty $(j=$ $1, \ldots, 7)$. Question 1 concerns income increase of more than $15 \%, \ldots$, question 7 an income decrease of more than $15 \%$. The variable $W_{j}$ takes the following values: 1 (very unlikely), .., 7 (very likely). Given Eq. (12) it is rather easy to compute the variance of the change income between now and next year (variable "Variance of 1-year change in future income"). In the calculation of "Variance of 1 -year change in future income" we take for each category of income change the midpoint (e.g. 7.5 in case of the category between 5 and 10).

In a sensitivity analysis we have also considered an alternative measure of income uncertainty. For each of the time-horizon lenghts described above, people are asked the following question:

"How certain do you feel about this income change?"

Individuals have to indicate their degree of uncertainty among four possibilities: very certain, rather certain, not very certain, not at all certain. Two categorical variables are then built: "... about inc. change (next $12 \mathrm{mths}$ )" and "... about inc. change (next 5 years)" for 12 months expectations and for 5 years expectations, respectively. This measure of uncertainty is in line with other studies (see, e.g. Hochguertel 2003) relying on subjective information about the income process.

5. Background characteristics: We add a number of individual characteristics, such as the number of adults and children and age classes (in dummies). In particular, the six age classes consist of age less than or equal 30 years, age between 31 and 40, age between 41 and 50, age between 51 and 60, age between 61 and 70, and age more than 70 . The latter class serves as reference group.

Table 1 reports summary statistics for the variables just described and used in the empirical study. In the empirical estimations, financial variables are used in real terms, as savings, financial wealth and income are deflated by means of the consumer price index. Deflating is also relevant for both the variable "Variance of 1-year change in future income"and the expected income growth question, which ask about nominal growth. We correct for price changes by using a measure of expected inflation derived from the following set of questions ${ }^{13}$ :

C1. "Do you expect prices in general to rise, to remain the same, or to go down in the next 12 months?"

C2. "By what percentage do you expect prices in general to rise in the next 12 months?"

\footnotetext{
13 Note that we cannot deflate the uncertainty about expected income changes given the way this piece of information is conveyed (see point 4).
} 
Table 1 Descriptive statistics

\begin{tabular}{|c|c|c|}
\hline Variable & Mean & SD \\
\hline Saving & 8081.70 & 14152.35 \\
\hline Realised income change & 673.69 & 10966.13 \\
\hline Expected income change (next 12 months) & 366.71 & 69250.65 \\
\hline Expected income change (next 5 years) & 1217.23 & 29640.63 \\
\hline Household income & 63170.58 & 36205.54 \\
\hline Variance of 1-year change in future income (vary) & 22.58 & 34.70 \\
\hline Very certain about inc. ch. (next 12 months) & 0.25 & 0.43 \\
\hline Rather certain about inc. ch. (next 12 months) & 0.65 & 0.48 \\
\hline Not very certain about inc. ch. (next 12 months) & 0.08 & 0.28 \\
\hline Not at all certain about inc. ch. (next 12 months) & 0.01 & 0.11 \\
\hline Very certain about inc. ch. (next 5 years) & 0.14 & 0.34 \\
\hline Rather certain about inc. ch. (next 5 years) & 0.66 & 0.47 \\
\hline Not very certain about inc. ch. (next 5 years) & 0.18 & 0.39 \\
\hline Not at all certain about inc. ch. (next 5 years) & 0.02 & 0.15 \\
\hline Number of household members & 2.51 & 1.28 \\
\hline Number of children & 0.71 & 1.08 \\
\hline Age $\leq 30$ & 0.04 & 0.19 \\
\hline $30<$ age $\leq 40$ & 0.19 & 0.39 \\
\hline $40<$ age $\leq 50$ & 0.28 & 0.45 \\
\hline $50<$ age $\leq 60$ & 0.21 & 0.41 \\
\hline $60<$ age $\leq 70$ & 0.20 & 0.40 \\
\hline Age $>70$ (reference group) & 0.09 & 0.29 \\
\hline
\end{tabular}

Number of observations $=6,390$. Saving, realized and expected income change, household income are expressed in real terms, i.e. in 1995 Dutch Guilders ( 1 euro $=2.20$ guilders)

D1. "Do you expect prices in general to rise, to remain the same, or to go down in the next 5 years?"

D2. "By what percentage do you expect prices in general to rise in the next 5 years?"

\section{Empirical implementation}

We take Eq. (9) as the starting point of our analysis. We extend this model by allowing for demographic variables (e.g. family size, number of children, age dummies) and for an unobserved individual effect $\alpha_{i} .{ }^{14}$ Since the dynamic model contains an individual

\footnotetext{
${ }^{14}$ It is important to correct for unobserved heterogeneity in the empirical specification. However, it is not easy to justify the fixed effect $\alpha_{i}$ of the empirical specification by means of the theoretical model. One can argue that the absolute risk aversion coefficient, $\theta$, is individual specific. As a result, the precautionary saving term (i.e. the last term of Eq. (9)) depends on the risk aversion coefficient $\theta_{i}$. In the empirical analysis we proxy this term, $\epsilon_{i t}^{*}$, as follows: $\epsilon_{i t}^{*}=\alpha_{i}+\delta v a r y_{i t}+\xi_{i t}$ where vary $y_{i t}$ is our subjective measure of income variance, $\alpha_{i}$ an unobserved individual effect, and $\xi_{i t}$ an idiosyncratic error term.
} 
effect $\alpha_{i}$ and our longitudinal dataset consists of six waves only, the standard within estimation technique yields inconsistent estimates. Procedures to estimate parameters of standard linear dynamic panel data models are discussed in numerous places (see, e.g. Arellano and Bond 1991; Blundell et al. 2000). To formulate the empirical model, two types of covariates are distinguished: $x_{i t}=\left(x_{i t}^{1}, x_{i t}^{2}\right)^{\prime}$. The empirical model has the following structure:

$$
s_{i t}=\gamma s_{i t-1}+x_{i t}^{\prime} \theta+\alpha_{i}+\epsilon_{i t}
$$

where we make the following assumptions:

1. all covariates are strictly exogenous: $\left\{x_{i t}^{1} ; t=1, \ldots, T\right\}$ and $\left\{x_{i t}^{2} ; t=1, \ldots, T\right\}$ uncorrelated with $\left\{\epsilon_{i t} ; t=1, \ldots, T\right\}$

2. $\left\{x_{i t}^{2} ; t=1, \ldots, T\right\}$ uncorrelated with $\alpha_{i}$

3. $\left\{\epsilon_{i t}^{1} ; t=1, \ldots, T\right\}$ are serially uncorrelated.

Time invariant regressors (e.g. gender, education level), which are assumed to be correlated with the individual effects, are subsumed in the individual effect and not incorporated explicitly in the model.

Define, for $t=3, \ldots, T$,

$$
u_{i t}=s_{i t}-\left[x_{i t}^{1 \prime} \theta_{1}+x_{i t}^{2 \prime} \theta_{2}+s_{i t-1 \gamma} \gamma\left(=\alpha_{i}+\epsilon_{i t}\right)\right.
$$

and

$$
\Delta u_{i t}=u_{i t}-u_{i t-1}\left(=\epsilon_{i t}-\epsilon_{i t-1}\right)
$$

The assumption of strict exogeneity implies the following moment conditions:

$$
\mathrm{E}\left[\Delta \boldsymbol{x}_{i t} \Delta u_{i t}\right]=0, \quad t=3, \ldots, T
$$

Since we assume that the $x_{i t}^{2}$-type of regressors are orthogonal to the individual effect $\alpha_{i}$, we can impose the following restrictions:

$$
\mathrm{E}\left[x_{i t}^{2} u_{i t}\right]=0, \quad t=2, \ldots, T
$$

Finally, the following moment condition is related to the lagged dependent variable:

$$
\mathrm{E}\left[s_{i t-2} \Delta u_{i t}\right]=0, \quad t=3, \ldots, T
$$

According to Blundell et al. (2000), the following additional moment restrictions based upon a mean stationarity assumption can be used to improve efficiency:

$$
E\left[u_{i t} \Delta s_{i t-1}\right]=0, \quad t=3, \ldots, T
$$

As already explained in the previous section, our saving measure suffers from measurement error. One may wonder how this error will affect the results. Let 
$s_{i t}=s_{i t}^{*}+v_{i t}$ where $s_{i t}^{*}$ and $s_{i t}$ denote "true" and measured saving respectively ( $v_{i t}$ is the measurement error in saving which is assumed to be I.I.D. distributed). In the presence of measurement error, the composite error term $u_{i t}$ is equal to: $u_{i t}=\alpha_{i}+\epsilon_{i t}+v_{i t}-\gamma v_{i t-1}$ (see Dynan 2000). In that case, the moment conditions (16) and (17) are still valid, conditions (18) and (19) however are not. Consequently, we do not use moment conditions (18) and (19) in our estimation procedure. Instead, in the main specification we impose the following moment conditions:

$$
\begin{aligned}
& \mathrm{E}\left[s_{i t-j} \Delta u_{i t}\right]=0, \quad j=3,4 \\
& E\left[u_{i t} \Delta s_{i t-j}\right]=0, \quad j=2,3
\end{aligned}
$$

The moment conditions (20) and (21) are valid under the assumption that the measurement errors $v_{i t}$ are transitory (i.e. independent over time). ${ }^{15}$ However, those two moment conditions are not valid if there is persistence in the measurement error. We carry out a Dif-Sargan test in order to check whether we can impose those moment conditions. Moreover, it can be shown that autocorrelation in the measurement error $s_{i t}$ also implies third order autocorrelation in $\Delta u_{i t}$. We test for the presence of third order autocorrelation in $\Delta u_{i t}$.

In order to improve efficiency, in particular the efficiency of the habit formation coefficient, we exploit additional information on saving behavior provided by the DHS. The following question is taken into consideration:

"How well can you manage on the total income of your household?

1 very hard, 2 hard, 3 neither hard nor easy, 4 easy, 5 very easy ".

On the basis of this information we construct a vector of instruments $x_{i t}^{3}$ consisting of three dummy variables ("neither hard or easy", "easy" and "very easy"). Given this information, we are able to exploit the following moment conditions in estimation:

$$
\begin{aligned}
& \mathrm{E}\left[x_{i t-2}^{3} \Delta u_{i t}\right]=0 \\
& E\left[\Delta x_{i t-1}^{3} u_{i t}\right]=0
\end{aligned}
$$

We think that we can interpret the $x_{i t}^{3}$ variables as qualitative measures of saving behavior. In order to check this claim, we first regress $s_{i t}$ on $x_{i t}^{3}$. It appears that the $x_{i t}^{3}$ variables predict saving $\left(R^{2}=0.14, F\right.$-statistic $\left.=360.52\right)$. Notice that these extra moment conditions are only valid if the measurement errors contained in the dummy variables $x_{i t}^{3}$ are not correlated with the measurement error in our saving measure $s_{i t}$. We then estimate the model without using moment conditions (22) and (23) and check the validity of restrictions (22) and (23) by means of a Dif-Sargan test.

To summarize, for a given specification, i.e., given choices of $\boldsymbol{x}_{i t}^{1}$ and $\boldsymbol{x}_{i t}^{2}$, moment conditions (16), (17), (20), (21 ), (22) and (23) can be used for the so-called "system GMM estimation". However, one may feel uncomfortable with the mean stationarity assumptions (cf. moment conditions (21) and (23)). Therefore, we have also estimated the model while dropping these moment conditions. The GMM estimation technique allows for any type of heteroskedasticity in $\alpha_{i}$ and $\epsilon_{i t}$. Sargan tests for overidentifying

\footnotetext{
15 Bond et al. (2001) already proposed the method to deal with transitory measurement problem which we employ in this paper.
} 
restrictions are used to test the validity of the moment restrictions. Moreover, we always present a difference Sargan test to check the validity of the moment conditions (21) and (23).

The assumption that the error terms $\epsilon_{i t}$ are serially uncorrelated seems quite strong, but it is common in this type of model. This assumption will be tested by checking for second order autocorrelation in the error terms in the differenced equations. To estimate the empirical models, we use the Stata routine xtabond2 which has been developed by Roodman (2006). This program implements the so-called "system-GMM" estimator. Moreover, it implements the Windmeijer (2005) finite-sample correction to the reported standard errors in the two-step estimation, without which those standard errors tend to be severely downward biased.

\section{Empirical results}

Table 2 reports results for the estimation of coefficients in Equation (9) according to several alternative specifications. Column (1) refers to the base model defined on the following specification (cf. moment conditions (16), (17), (20), (21), (22) and (23)): $x_{i t}^{1}$ includes the following variables: number of adults (in $\left.\operatorname{logs}\right), \ln (1+$ number of children), realized income change, ${ }^{16}$ both short and long run expectations about future income changes and the precautionary saving term, i.e. the degree of uncertainty about future income changes. $x_{i t}^{2}$ includes a full set of year and age class dummies.

The base model passes some mis-specification tests. The Hansen test in column (1) suggests that the over-identifying restrictions cannot be rejected (the value of the Hansen statistic is 101.5 (degrees of freedom 95) with a $p$ value of 0.306 ). The results of the difference Sargan test indicate that the moment conditions (17) are valid (the value of the Dif-Sargan statistic is 51.13 with a $p$ value of 0.112 ). We also perform a Dif-Sargan in order to check whether it is allowed to impose the moment conditions (22) and (23). The validity of those moment restrictions is not rejected $\left(\chi_{24}^{2}=30.97\right.$, $p$ value $=0.155)$. In comparison with the base model the parameter estimate of the habit formation coefficient, 0.145 , does not change dramatically if we do not exploit moment conditions (22) and (23) in estimation. However, this coefficient estimate is less precise albeit significant at the $10 \%$ level ( $p$ value 0.094$){ }^{17}$

In the empirical model it is assumed that the error term is serially uncorrelated. The second order autocorrelation test does not indicate rejection of the assumption that $\left\{\epsilon_{i t}^{1} ; t=1, \ldots, T\right\}$ are serially uncorrelated. In Sect. 4 it is mentioned that measurement error in saving could cause third order serial correlation. We do not find evidence for this (see Table 2). When using the alternative saving measure computed as described in footnote 12 , our estimation results barely change. Therefore, one can conclude that the estimation results are not "dominated" by the imputed continuous savings data for those who do not put money aside.

\footnotetext{
${ }^{16}$ In Sect. 2 we already mentioned that in the theoretical model, income is assumed to be a strictly exogenous variable.

17 We obtain a much more precise coefficient estimate of the habit formation coefficient if we ignore the possibility that saving is measured with error (i.e. if we use moment conditions (18) and (19) instead of (20) and (21)): $\hat{\gamma}=0.185, \mathrm{SD}(\hat{\gamma})=0.066$.
} 


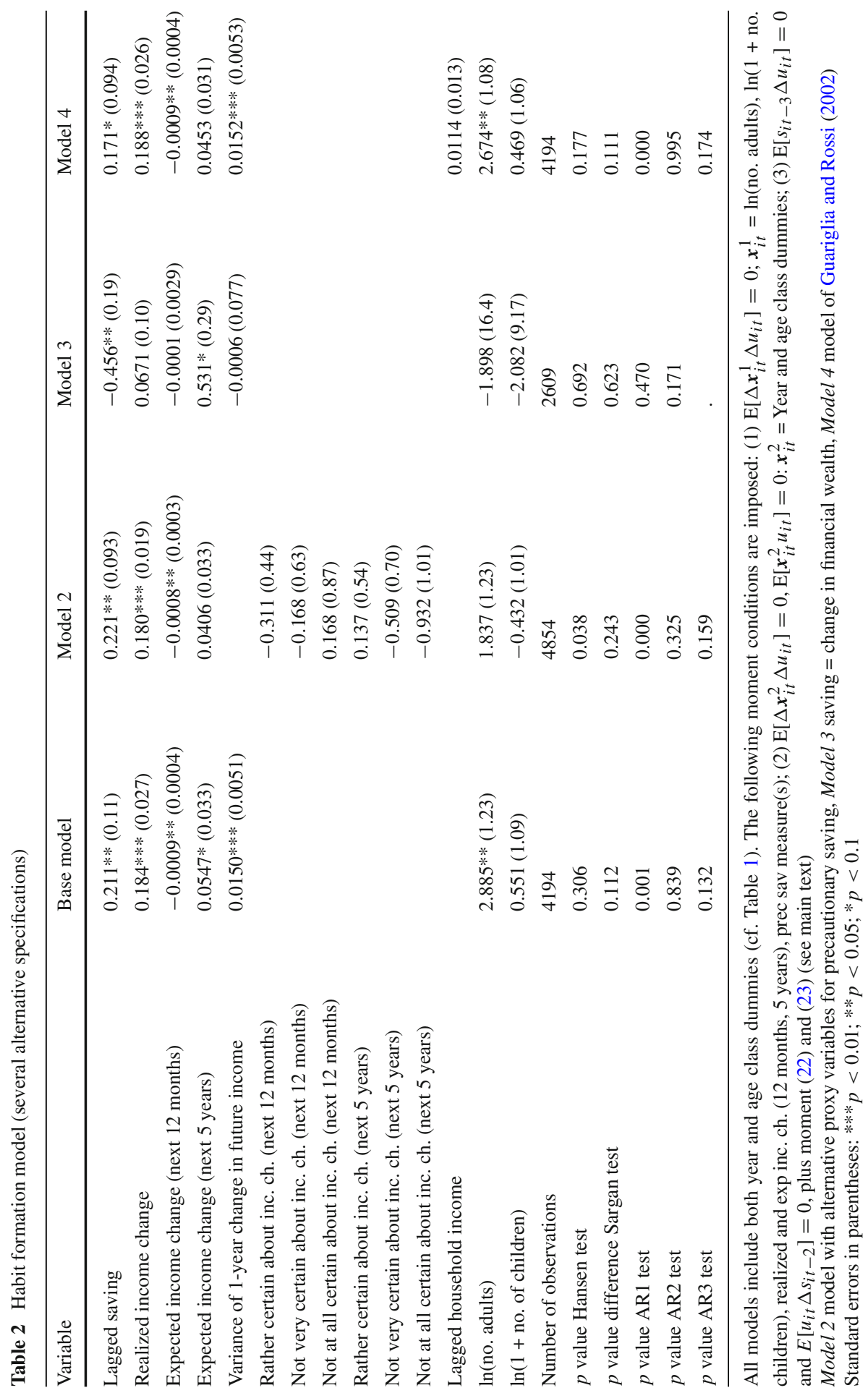


Moreover, we follow the suggestion of Nickell and Nicolitsas (1999) and check the requirement of instrument relevance by means of two $F$ tests. ${ }^{18}$ We carry out two first stage regressions. In the first one we perform a random effects regression of $\Delta s_{i t-1}$ on $\Delta x_{i t}$ (see Eq. 13), $s_{i t-3}$ and $x_{i t-2}^{3}$ (see equation (22)). Then we test the joint hypothesis that the coefficients corresponding to "remaining" instruments $s_{i t-3}$ and $x_{i t-2}^{3}$ are equal to zero. The second $F$ test checks whether $\Delta s_{i t-2}, \Delta s_{i t-3}$ and $\Delta x_{i t-1}^{3}$ explain $s_{i t-1}$ (after having corrected for $x_{i t}^{2}$ ). We find the following $F$ values ( $p$ values): 13.93 (0.000) for the first $F$ test and 50.14 (0.001) for the second one. ${ }^{19}$ Stock and Watson (2003) have formulated a rule of thumb which says that the $F$ value should exceed 10 in order to circumvent the problem of weak instruments. In our analysis, both first stage regressions satisfy this requirement.

In the base model, the estimated habit formation parameter $\gamma$ is equal to 0.211 and differs significantly from 0 at the 5 percent level ( $t$ value 1.96). It is interesting to compare these results with those presented in Table 3, reporting OLS, Within Groups and First Difference GMM estimations. In all regressions, year and age class dummies are included but not reported in the table for space reasons. If we do not allow for unobserved heterogeneity, the OLS estimate of the habit formation coefficient gets considerably larger: 0.434 ( $t$ value 32.2 ). This result is not surprising, as it is well known that if unobserved heterogeneity is neglected, then the OLS estimate is upward biased (see Blundell et al. 2000). This result indicates that the unobserved heterogeneity may partly explain the positive raw correlation between saving and lagged saving. When performing the Within Groups estimation, the coefficient corresponding to lagged saving is negative $(-0.12)$ and significant $(t$ value -6.48$)$. This result is also in line with Blundell et al. (2000), who report that if $T$ (=the number of waves in the panel) is small, the within estimate of the lagged dependent variable is downward biased. Notice however that in Blundell et al. (2000) no other regressors are considered when assessing the direction of the bias. The final column of Table 3 reports results from the First Difference GMM estimation in which the possibility that saving is measured with error is taken into account. ${ }^{20}$ One would expect the first-difference GMM estimate to fall between the OLS and the within-group estimate. This is indeed the case: the habit formation coefficient is slightly positive (0.027) and insignificant ( $t$ value 0.26 ). Notice that this estimate falls rather close to the within-group estimate.

Another feature to emphasize is that the estimate of the habit formation coefficient $\gamma$ is close to the one for the realized income changes parameter (the estimated $\gamma$ corresponding to lagged saving is equal to 0.211 whereas the coefficient corresponding to "realized income change" $\frac{\gamma}{1+r}$ is 0.184$)$. This is in line with the theoretical model: in Eq. (9) the lagged saving coefficient should be rather close to the one of "realised income change".

\footnotetext{
18 We have to carry out two $F$ tests because we estimate the parameters of the habit formation model by means of system-GMM which involves both level and first-difference moments.

19 The additional instruments stemming from the question "How well can you manage on the total income of your household?" enter significantly into the second first stage regression: the $F$-statistic ( $p$ value) is equal to 10.32 (0.000). However, those dummies are not jointly significant in the other first stage regression.

20 Table 3 also reports the moment conditions used in estimation.
} 
Table 3 OLS, Within and first differences GMM estimation results

\begin{tabular}{|c|c|c|c|}
\hline Variable & OLS & Within estimation & First diff. GMM \\
\hline Lagged saving & $0.434 * * *(0.013)$ & $-0.121 * * *(0.019)$ & $0.0273(0.11)$ \\
\hline Realized income change & $0.213 * * *(0.016)$ & $0.157 * * *(0.017)$ & $0.173 * * *(0.018)$ \\
\hline $\begin{array}{l}\text { Expected income change } \\
\text { (next } 12 \text { months) }\end{array}$ & $-0.002(0.002)$ & $-0.0009(0.002)$ & $-0.0007 * * *(0.0002)$ \\
\hline $\begin{array}{l}\text { Expected income change } \\
\text { (next } 5 \text { years) }\end{array}$ & $0.023(0.021)$ & $0.015(0.026)$ & $0.021(0.033)$ \\
\hline $\begin{array}{l}\text { Variance of 1-year change } \\
\text { in future income }\end{array}$ & $0.003(0.006)$ & $0.003(0.008)$ & $0.010(0.006)$ \\
\hline $\ln$ (no. of adults) & $3.082 * * *(0.69)$ & $-0.324(2.72)$ & $0.791(2.07)$ \\
\hline $\ln (1+$ no. of children $)$ & $-1.478 * * *(0.44)$ & $1.139(1.62)$ & $1.535(1.10)$ \\
\hline Number of observations & 4194 & 4194 & 2722 \\
\hline Number of households & & 1449 & 1338 \\
\hline$R^{2}$ & & 0.06 & \\
\hline Hansen test statistic & & & 40.85 \\
\hline Degrees of freedom Hansen test & & & 49 \\
\hline$p$ value Hansen test & & & 0.790 \\
\hline $\begin{array}{l}\text { Arellano-Bond test for AR1 } \\
\text { in first differences }\end{array}$ & & & -2.807 \\
\hline$p$ value $\mathrm{AR}(1)$ test & & & 0.005 \\
\hline $\begin{array}{l}\text { Arellano-Bond test for AR2 } \\
\text { in first differences }\end{array}$ & & & -0.902 \\
\hline$p$ value $\mathrm{AR}(2)$ test & & & 0.367 \\
\hline $\begin{array}{l}\text { Arellano-Bond test for AR3 } \\
\text { in first differences }\end{array}$ & & & 1.077 \\
\hline$p$ value $\mathrm{AR}(3)$ test & & & 0.281 \\
\hline
\end{tabular}

All models include a full set of both year and age class dummies (see Table 1). The following moment conditions are imposed: (1) $\mathrm{E}\left[\Delta \boldsymbol{x}_{i t} \Delta u_{i t}\right]=0$ where $\boldsymbol{x}_{i t}=\ln$ (no. adults), $\ln (1+$ no. children), prec sav measure(s), realized income ch., year and age class dummies, realized inc. ch., exp inc. ch. (12 months and 5 years); (2) $\mathrm{E}\left[s_{i t-3} \Delta u_{i t}\right]=0$, plus moment (22) (see main text)

Standard errors in parentheses: $* * * p<0.01$; ** $p<0.05$; $* p<0.1$

As a proxy for expected income changes $\sum_{\tau=t}^{\infty}(1+r)^{t-\tau} E_{t} \Delta y_{\tau}$ we use variables "Expected income change (next $12 \mathrm{mths}$ )" and "Expected income change (next 5 years)". Their coefficients should be negative $\left(-\left(1-\frac{\gamma}{1+r}\right)\right)$ because of the "saving for a rainy day" argument (see Campbell 1987). Obviously, this proxy is not perfect. The estimated coefficient of "Expected income change (next year)" is negative and differs significantly from 0 , whereas the estimated coefficient for "Expected income change (next 5 years)" has the unexpected sign. Given the small estimated value of $\gamma(0.211)$ and for reasonable values of the real interest rate, we would expect an estimated coefficient associated with "Expected income change (next year)" of around -0.8 . However, we obtain a much smaller value. This suggests that either people have a short time horizon or are liquidity constrained. ${ }^{21}$

${ }^{21}$ Liquidity constraints effectively shortens the time horizon as shown by e.g. Runkle (1991). 
In the base model, we capture the precautionary saving motive by including the variable "Variance of 1-year change in future income" defined in the data section. We find that the precautionary saving motive plays a significant positive role in saving behavior. This finding is in line with the evidence provided by Guariglia and Rossi (2002). Given the small estimated value of $\gamma(0.211)$ this result turns out to coincide with the predictions of the theoretical model: the weaker the habit formation the stronger the precautionary saving motive.

As for the demographic variables, we observe (see Table 2) that saving behavior is affected significantly by both the number of adults and household composition. The age class dummies are jointly insignificant. ${ }^{22}$ This result might be explained by the fact that we included a full set of year dummies. In a sensitivity analysis, we also extend the model by including labor market status dummies. Contrary to both Meghir and Weber (1996) and Carrasco et al. (2005), we do not find any significant effect of labor market variables.

To summarize, our evidence indicates that habit formation is a relevant phenomenon. In that respect, our results differ from those of Guariglia and Rossi (2002), as they get a negative, strongly significant estimate for $\gamma$. As already mentioned in the introduction, they interpret this negative sign as an indicator of "durability" in Deaton (1992) sense. Dynan (2000) estimates a similar Euler equation as Guariglia and Rossi (2002) but she considers food consumption instead of total consumption. Dynan (2000) also obtains a negative estimate for $\gamma$, albeit insignificant. Since food is a clearly non-durable good, her negative estimate cannot be explained by means of a durability argument.

However, another interpretation for the findings of Guariglia and Rossi (2002) and Dynan (2000) can be provided. Their estimates come from the Euler equation for consumption rather than from a closed form solution similar to our Eq. (13). The data at their disposal refers to consumption expenditures (rather than savings) which are presumably measured with considerable error. Such measurement errors might be responsible for a strong spurious negative correlation between differences in current $\left(\Delta c_{i t}\right)$ and past consumption levels $\left(\Delta c_{i t-1}\right)$. As one can infer from the analysis by Dynan (2000), the OLS estimate of the habit formation parameter $\gamma$ is severely biased downward: even if the true habit formation coefficient is greater than zero, the estimated coefficient might be lower than zero and no standard attenuation bias towards zero occurs. ${ }^{23}$ Guariglia and Rossi (2002) indeed performed a formal test of instrument validity, as in Nickell and Nicolitsas (1999). They regressed the first-differences of the lagged dependent variable and their uncertainty term on all the exogenous variables

\footnotetext{
22 The $p$ value of the Wald test of the hypothesis that all five age coefficients are jointly equal to zero is 0.67 .

23 Dynan (2000) shows that the error term of the Euler equation has the following form: $\zeta_{i t}+v_{i} t-(1+$ $\gamma) v_{i t-1}+\gamma v_{i t-2}$, where $z e t a_{i t}$ and $v_{i \tau}, \quad \tau=t, t-1, t-2$ denote the forecast error and the measurement errors in consumption respectively. If one ignores other RHS variables (this is a simplifying assumption) and if one assumes that the measurement error is IID distributed, one can easily show that the OLS estimate of the habit formation parameter $\gamma$, converges to: plim $\hat{\gamma}_{O L S}=\gamma-(1+2 \gamma) \frac{\sigma_{v}^{2}}{\operatorname{var}\left(\Delta c_{i t-1}\right)}$. If the measurement errors are sizable, it is well conceivable that the OLS estimate of the habit formation coefficient converges to a negative number.
} 
in their Eq. (13) plus the remaining instruments, using a GLS random-effects method. They then tested for the joint significance of the later instruments, using a Wald test. In both cases, they obtained $p$ values equal to 0.00 , indicating that the instruments generally have sufficient explanatory power. Moreover, they also used a system-GMM estimator, proposed by Blundell and Bond (1998), which combines the standard set of equations in first differences with suitably lagged first-differences as instruments. The latter instruments are generally highly informative and allow to overcome the weak instrument bias. In other words, the empirical results of Guariglia and Rossi (2002) should be taken seriously.

In order to better understand the role of precautionary saving, we perform a sensitivity analysis by using an alternative measure of income uncertainty. Instead of the measure employed by Das and Donkers (1999), we only consider the information related to how (un)certain respondents are about income changes next year and 5 years ahead (see also Hochguertel 2003). The results are summarized in Table 2, column "model 2". In this case we do not find any evidence for precautionary saving. The other parameter estimates are not much affected by the choice of the precautionary saving measure.

It is worth noting that our definition of saving is based on information about money put aside and wealth. An alternative definition would be computing first differences in wealth. In the latter specification, our empirical model would take the following form:

$$
\Delta A_{t}=\gamma \Delta A_{t-1}+x_{i t}^{\prime} \theta+\alpha_{i}+\epsilon_{i t}
$$

Obviously, there exists a strong negative correlation between $\Delta A_{t}$ and $\Delta A_{t-1}$ because $A_{t}$ is measured with considerable error. If we estimate Eq. (24) by means of OLS we get a negative estimate for $\gamma$. Even by applying GMM (see Table 2, column "Model 3"), we obtain a significant negative estimate of $\gamma:-0.46$ (standard error $0.19)$. Given the fact that $A_{t}$ is measured with error, we have employed the following moment conditions instead of Eqs. (20) and (21):

$$
\begin{aligned}
E\left[\Delta A_{i t-4} \Delta u_{i t}\right] & =0 \\
E\left[u_{i t} \Delta\left(\Delta A_{i t-3}\right)\right] & =0
\end{aligned}
$$

This procedure would imply a loss of one year of observations, the number of observations dropping from 4,194 to 2,609. More importantly, the problem with the system GMM estimation is that we do not have good instruments for $\Delta A_{i t-1}$ (and $\Delta\left(\Delta A_{i t-1}\right)$ ) at our disposal, because this saving measure is extremely noisy. ${ }^{24}$ As a consequence, we have decided not to build (and work with) the saving measure with information about differences in wealth.

Finally, we consider Guariglia and Rossi (2002) extension of the model of Alessie and Lusardi (1997) (cf. Eq. 11). This model implies that we should extend the empirical model (13) by adding lagged consumption to the right hand side:

\footnotetext{
24 As we did for the main specification (cf. Table 2), we perform two $F$ tests to investigate whether we are able to predict the endogenous RHS variables $\Delta A_{i t-1}$ and $\Delta\left(\Delta A_{i t-1}\right)$. Unfortunately, we end up with low $F$ values and high $p$ values. For the $\Delta A_{i t-1}$ regression the $F$ value ( $p$ value) is equal to $2.50(0.041)$ and for the $\Delta\left(\Delta A_{i t-1}\right)$ regression equal to $1.76(0.135)$.
} 


$$
s_{i t}=\zeta_{1} s_{i t-1}+x_{i t}^{\prime} \theta+\zeta_{2} c_{i t-1}+\alpha_{i}+\epsilon_{i t}
$$

Since we do not observe consumption directly, we rewrite Eq. (27) as follows:

$$
s_{i t}=\left(\zeta_{1}-\zeta_{2}\right) s_{i t-1}+x_{i t}^{\prime} \theta+\zeta_{2} Y_{i t-1}+\alpha_{i}+\epsilon_{i t}
$$

where $Y_{i t-1}=$ total household income in year $t-1$. In the estimation of Eq. (2) we assume that $Y_{i t-1}$ is a strictly exogenous variable but we allow for a possible correlation between this variable and the individual effect. It appears that the estimated coefficient $\zeta_{2}$ is rather small and not significantly different from 0 (see Table 2, column "Model 4"). This result can be explained by $\rho$ is approximately equal to $r$ (if they are exactly equal then $\zeta_{2}=0$ ). In other words, we do not reject the hypothesis that Guariglia and Rossi (2002) model and the one of Alessie and Lusardi (1997) are observationally equivalent. This result should be interpreted with care. If $r$ is close to $\rho$, one needs a lot of observations in order to get a significant estimate for $\zeta_{2}$. Our dataset is presumably too small in order to get such a precise estimate.

\section{Conclusions}

This paper focuses on the role of habit formation in individual preferences. In this study, the model of Alessie and Lusardi (1997) and its extension by Guariglia and Rossi (2002) are considered. Our empirical specifications are based on their closedform solutions, where saving is expressed as a function of lagged saving and other regressors. In our study, we use a longitudinal data set from the Netherlands that allows us to disentangle the role of habit formation from unobserved heterogeneity. Contrary to other studies using survey data (using the Euler equation for consumption, both Dynan (2000) and Guariglia and Rossi (2002) find negative estimates of the habit formation coefficient), we find evidence in favor of habit formation. However, the magnitude of the habit formation coefficient is rather small. Income uncertainty seems also to affect saving behavior of Dutch households.

We should note that the habit formation model is not fully accepted by the data. We find evidence in favor of a short planning horizon and liquidity constraints. More theoretical research seems to be needed in order to investigate the joint impact of liquidity constraints and habit formation.

Finally, up to this point we have not looked at preference interdependence (Maurer and Meier 2008), which might (partially) explain the significance of the habit formation coefficient we have found. This should be on the agenda for future research.

Acknowledgments We thank Arie Kapteyn, Jan van Ours, Mario Padula, Arthur van Soest and seminar participants at the University of Lausanne for their helpful comments. We are very grateful to two anonymous referees for their useful suggestions. Any remaining errors are our responsibility. In this paper, use is made of data of the DNB Household Survey (formerly known as CentER Savings Survey); we thank CentERdata at Tilburg University for supplying them.

Open Access This article is distributed under the terms of the Creative Commons Attribution Noncommercial License which permits any noncommercial use, distribution, and reproduction in any medium, provided the original author(s) and source are credited. 


\section{References}

Abel A (1990) Asset prices under habit formation and catching up with the Jones. Am Econ Rev 40:38-42 Alessie R, Hochguertel S, van Soest A (2002) Household portfolios in the Netherlands. In: Guiso L, Haliassos M, Jappelli T (eds) Household portfolios. University Press, Cambridge pp 341-388

Alessie R, Lusardi A (1997) Consumption, saving and habit formation. Econ Lett 55:103-108

Angelini V (2009) Consumption and habit formation when time horizon is finite. Econ Lett (forthcoming)

Arellano M, Bond S (1991) Some tests of specification for panel data: Monte Carlo evidence and an application to employment equations. Rev Econ Stud 58:277-297

Blundell R, Bond S (1998) Initial conditions and moment restrictions in dynamic panel data models. J Econometrics 87:115-143

Blundell R, Bond S, Windmeijer F (2000) Estimation in dynamic panel data models: improving on the performance of the standard GMM estimators. In: Baltagi B (ed) Nonstationary panels, panel cointegration, and dynamic panels. Advances in econometrics, vol 15. JAI Press, Amsterdam

Bond S, Hoeffler A, Temple J (2001) GMM estimation of empirical growth models. CEPR discussion paper 3048

Caballero R (1990) Consumption puzzles and precautionary savings. J Monet Econ 25:113-136

Campbell J (1987) Does saving anticipate declining labor income? An alternative test of the permanent income hypothesis. Econometrica 55:1249-1273

Campbell J, Cochrane J (1999) By force of habit: a consumption-based explanation of aggregate stock market behaviour. J Polit Econ 107:205-251

Campbell J, Deaton A (1989) Why is consumption so smooth?. Rev Econ Stud 56:357-374

Carrasco R, Labeaga J, Lopez-salido J (2005) Consumption and habits: evidence from panel data. Econ J 115:144-165

Carroll C (2002) Risky habits and the marginal propensity to consume out of permanent income. Computing in economics and finance, vol 42. Society for Computational Economics

Carroll C, Overland J, Weil D (2000) Saving and growth with habit formation. Am Econ Rev 90:341-355

Das M, Donkers B (1999) How certain are Dutch households about future income? An empirical analysis. Rev Income Wealth 45:325-338

Deaton A (1992) Understanding consumption. Clarendon Press, Oxford

Dunn K, Singleton K (1986) Modeling the term structure of interest rates under non-separable utility and durability of goods. J Financ Econ 17:27-55

Dynan K (2000) Habit formation in consumer preferences: evidence from panel data. Am Econ Rev 90: 391-406

Ferson W, Constantinides G (1991) Habit persistence and durability in aggregate consumption: empirical tests. J Financ Econ 29:199-240

Flavin M (1981) The adjustment of consumption to changing expectations about future income. J Polit Econ 89:974-1009

Guariglia A, Rossi M (2002) Consumption, habit formation and precautionary saving: evidence from the British Household Panel Survey. Oxf Econ Pap 54:1-19

Hochguertel S (2003) Precautionary motives and portfolio decisions. J Appl Econ 18:61-77

Hotz J, Kydland F, Sedlacek G (1988) Intertemporal preferences and labor supply. Econometrica 56: 335-360

Malley J, Molana H (2006) Further evidence from aggregate data on the life-cycle-permanent-income model. Empir Econ 31:1025-1041

Maurer J, Meier A (2008) Smooth it like the 'Joneses'? Estimating peer-group effects in intertemporal consumption choice. Econ J 118:454-476

Meghir C, Weber G (1996) Intertemporal nonseparability or borrowing restrictions? A disaggregate analysis using a U.S. consumption panel. Econometrica 64:1151-1181

Mehra R, Prescott E (1985) The equity premium: a puzzle. J Monet Econ 15:145-161

Nickell S, Nicolitsas D (1999) How does financial pressure affect firms? Eur Econ Rev 43:1435-1456

Pollak R (1970) Habit formation and dynamic demand function. J Polit Econ 78:745-763

Roodman D (2006) How to do xtabond2: an introduction to "difference" and "system" GMM in Stata. Center for Global Development Working Paper 103

Runkle D (1991) Liquidity constraints and the permanent income hypothesis: evidence from panel data. J Monet Econ 27:73-98

Spinnewijn F (1981) Rational habit formation. Eur Econ Rev 15:91-109 
Stock J, Watson M (2003) Introduction to econometrics. Addison-Wesley, Boston

Weil P (1989) The equity premium puzzle and the risk-free rate puzzle. J Monet Econ 24:401-421

Weil P (1993) Precautionary savings and the permanent income hypothesis. Rev Econ Stud 60:367-381

Windmeijer F (2005) A finite sample correction for the variance of linear efficient two-step GMM estimators. J Econom 126:25-51 